\title{
Usefulness of Left Atrial Expansion Index for Predicting Recurrent Stroke
}

\author{
Shih-Hung Hsiao ${ }^{1}$ \\ ${ }^{1}$ E-Da Hospital
}

August 26, 2020

\begin{abstract}
Background: Although left atrial (LA) expansion index is associated with cardiovascular prognosis, whether it affects recurrent strokes is still unknown. Methods: This study enrolled 176 patients hospitalized for a first ischemic stroke. Stroke subtype was classified as cardioembolic stroke (CE), noncardioembolic stroke (NCE), embolic stroke of undetermined source (ESUS) or transient ischemic attack. The LA expansion index was calculated as (Volmax-Volmin) x 100\%/Volmin, where Volmax was defined as maximal LA volume and Volmin as minimal LA volume. The study endpoint was recurrent ischemic stroke. Results: Over a 5-year (mean 4.9 years) follow-up period, 21 (11.9\%) participants reached the study endpoint, including 10 with CE, 5 with NCE and 6 with ESUS. The LA expansion index was lower in the event groups compared to the non-event group. For predicting recurrent stroke, LA expansion index $<62.5 \%$ (76\% sensitivity and $68 \%$ specificity) was superior to LA volume and E/e'. Kaplan-Meier curves revealed that the 5-year cumulative recurrent stroke rate in patients with LA expansion index $<$ $62.5 \%$ was $23.9 \%$, which was significantly higher than the 5 -year cumulative recurrent stroke rate of $4.6 \%$ in patients with LA expansion index $>62.5 \%$ ( $\log$ rank $\mathrm{p}<0.001)$. The LA expansion index was a significant independent predictor of recurrent stroke (HR 0.87; 95\% CI 0.782-0.968 per 10\% increase in LA expansion index; p 0.011). Conclusion: The LA expansion index is useful for predicting recurrent stroke.
\end{abstract}

\section{Hosted file}

LAEI and recurrent stroke.doc available at https://authorea.com/users/353921/articles/477643usefulness-of-left-atrial-expansion-index-for-predicting-recurrent-stroke

\section{Hosted file}

table 1 return.doc available at https://authorea.com/users/353921/articles/477643-usefulnessof-left-atrial-expansion-index-for-predicting-recurrent-stroke

\section{Hosted file}

table 2 return.doc available at https://authorea.com/users/353921/articles/477643-usefulnessof-left-atrial-expansion-index-for-predicting-recurrent-stroke 


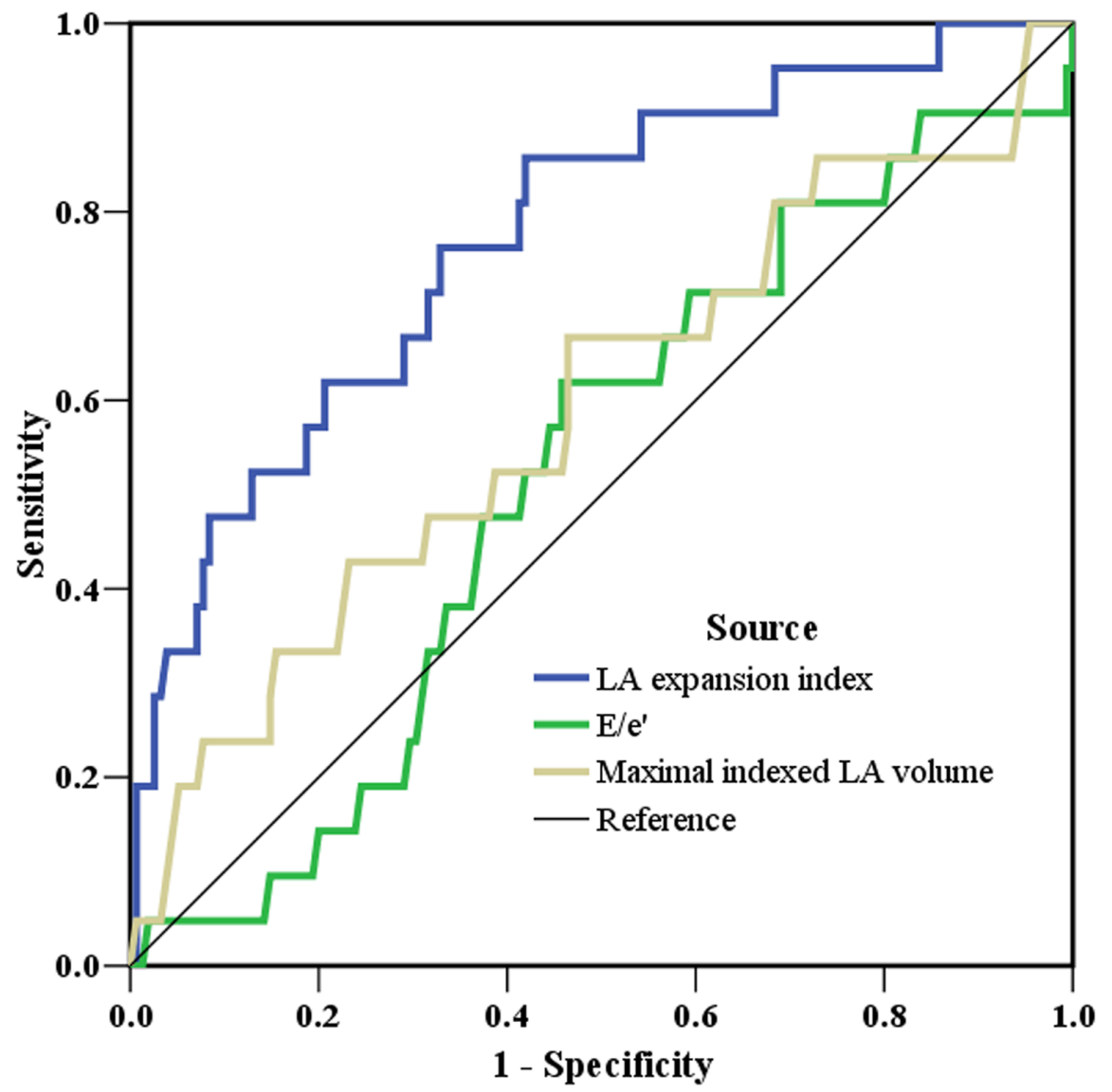




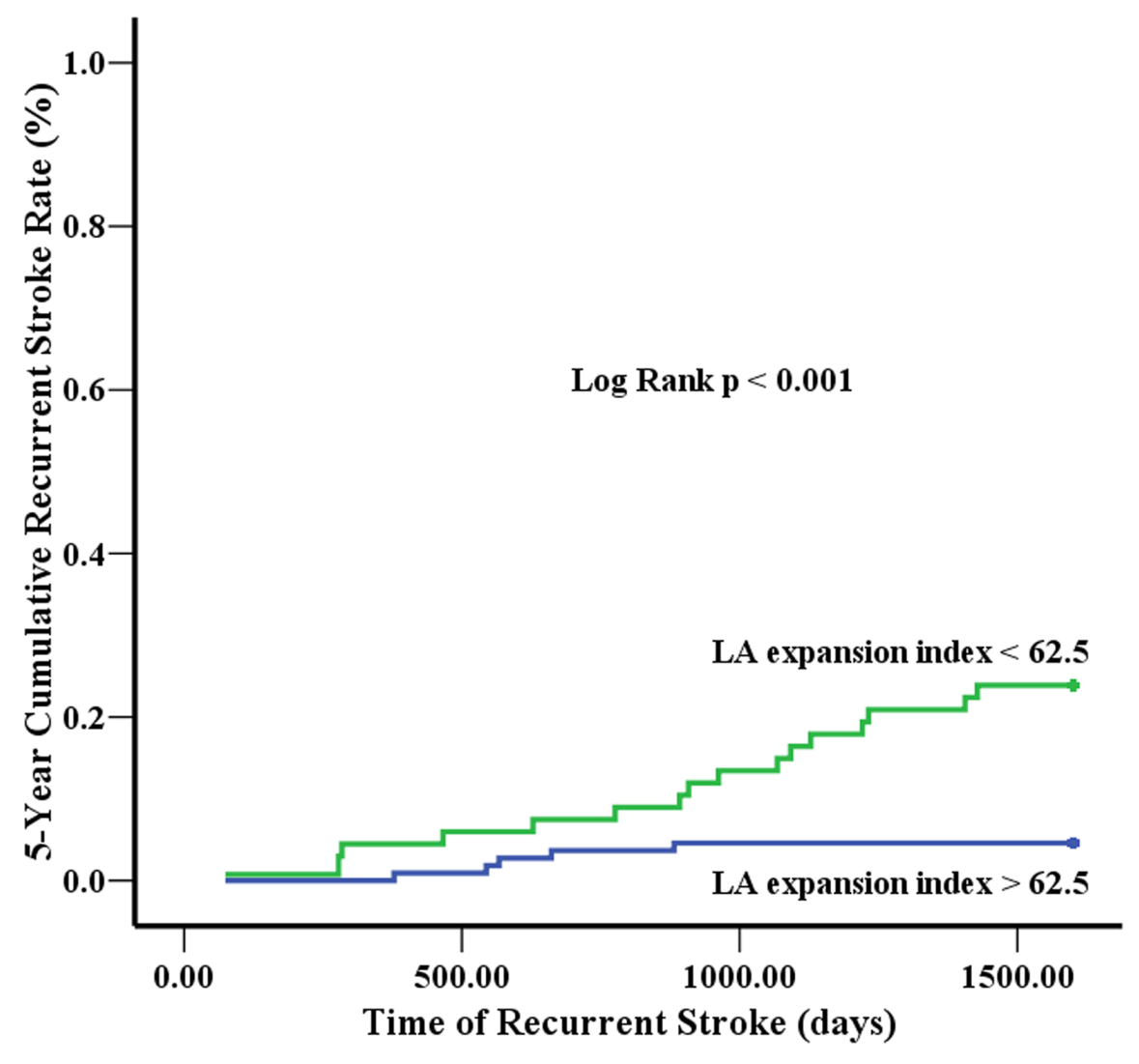




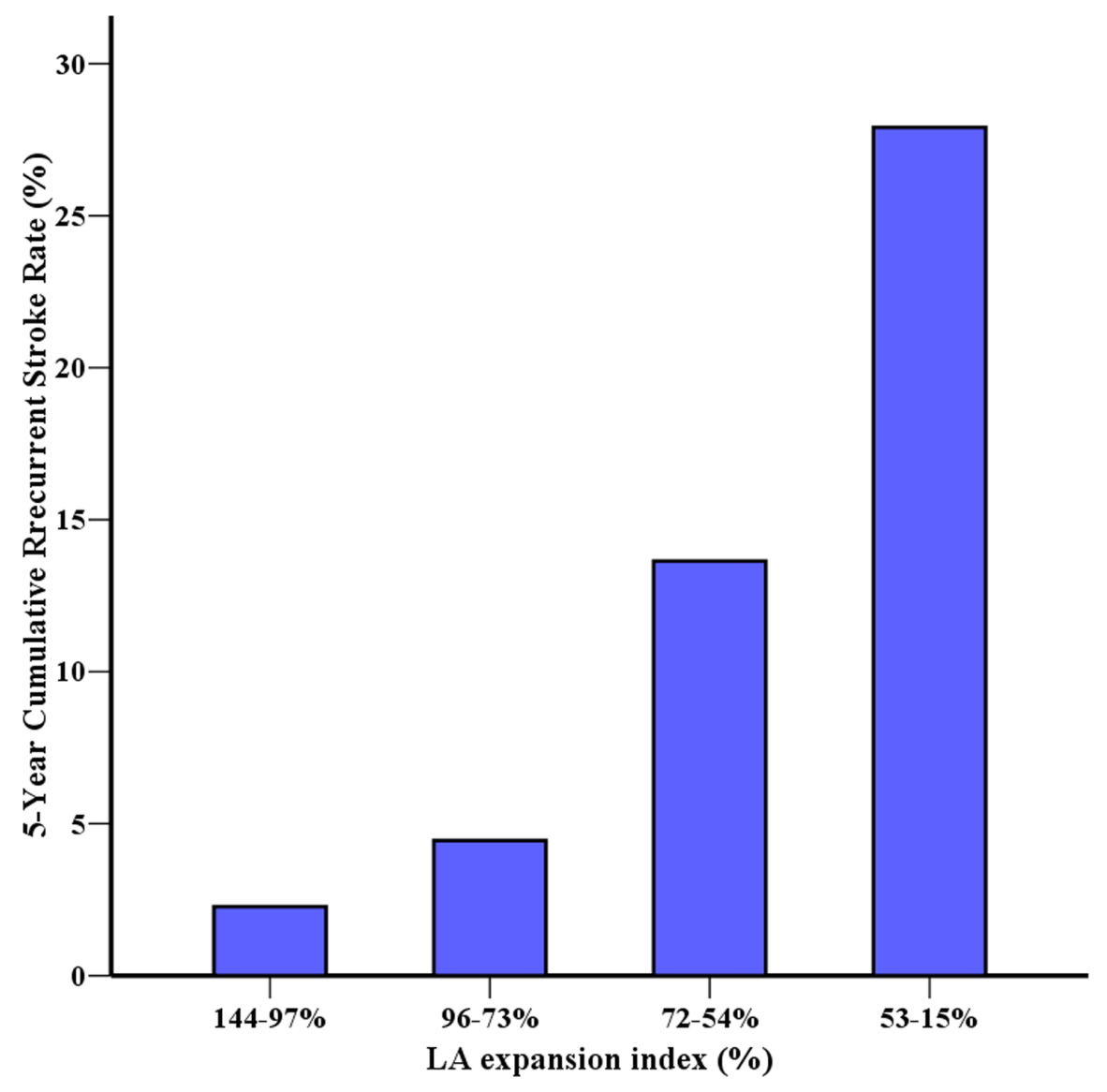

